\title{
A new highly sensitive and specific overnight combined screening and diagnostic test for primary aldosteronism
}

\author{
Vaios Tsiavos', Athina Markou'1, Labrini Papanastasiou'1, Theodora Kounadi', \\ loannis I Androulakis', Nick Voulgaris', Aglaia Zachaki ${ }^{1}$, Eva Kassi ${ }^{2}$, \\ Gregory Kaltsas ${ }^{3}$, George P Chrousos ${ }^{4}$ and George P Piaditis ${ }^{1}$ \\ 'Department of Endocrinology and Diabetes Centre, "G. Gennimatas" Athens General Hospital, Athens, \\ Greece, ${ }^{2}$ Department of Biological Chemistry, Medical School, National and Kapodistrian University of \\ Athens, Athens, Greece, ${ }^{3}$ Department of Pathophysiology, Laikon Hospital, School of Medicine, \\ University of Athens, Athens, Greece, and 'First Department of Paediatrics, Children's Hospital Aghia \\ Sophia, School of Medicine, University of Athens, Athens, Greece
}

\author{
Correspondence \\ should be addressed \\ to $\mathrm{V}$ Tsiavos \\ Email \\ vaiostsiavos@gmail.com
}

\section{Abstract}

Context: Primary aldosteronism (PA) is the most common cause of endocrine hypertension that is diagnosed following a two-step process: an initial screening test, based on the serum aldosterone-to-renin ratio (ARR), followed by a relatively laborious and time-consuming confirmatory test to document autonomous aldosterone (ALD) secretion. Objective: The aim of this study is to develop a simple overnight test for the early and definite diagnosis of PA. Patients and methods: Totally, 148 hypertensive patients underwent a fludrocortisone-dexamethasone suppression test (FDST) and the new overnight diagnostic test (DCVT) using pharmaceutical RAAS (renin-angiotensin-aldosterone system) blockade with dexamethasone, captopril and valsartan.

Results: Of the 148 patients, 45 were diagnosed as having PA and they all normalized their elevated blood pressure (BP) after administration of spironolactone or eplerenone. The remaining 103 patients were considered as having essential hypertension and served as controls. Using ROC analysis, the estimated sensitivity and specificity were 91 and $100 \%$, respectively, for the post-FDST ARR, whereas $98 \%$ and $89 \%$ and $100 \%$ and $82 \%$ for the post-DCVT ARR and post-DCVT ALD, respectively, with selected cutoffs of $0.32 \mathrm{ng} / \mathrm{dL} / \mu \mathrm{U} / \mathrm{mL}$ and $3 \mathrm{ng} / \mathrm{dL}$ respectively. However, considering these cutoffs simultaneously, the estimated sensitivity and specificity were 98 and $100 \%$ respectively. Applying these cutoffs, the diagnosis of PA was confirmed in 44 (98\%) of the 45 patients who were considered to have the disease. Conclusions: In this study, a highly sensitive and specific, low-cost, rapid, safe, and easy-to-perform diagnostic test (DCVT) for PA is described, which could be utilized on an outpatient basis potentially substituting conventional laborious testing.

\section{Introduction}

Primary aldosteronism (PA) is the most common cause of endocrine hypertension secondary to autonomous or inappropriately elevated aldosterone production from the adrenals. The prevalence of PA varies considerably among hypertensive patients in different studies, depending on patient selection, diagnostic methodology employed, and severity of arterial hypertension (1, 2, 3, 4).

www.eje-online.org DOI: 10.1530/EJE-16-0003
() 2016 European Society of Endocrinology Printed in Great Britain
The current standard practice for the diagnosis of PA is to initially apply a screening test using the calculation of basal aldosterone-to-renin ratio (ARR) followed by a confirmatory test to document autonomous aldosterone secretion, such as the oral sodium loading test, saline infusion test (SIT), fludrocortisone suppression test (FST), or captopril challenge test. Using current methodology, 
the estimated prevalence of PA has been found to range from 4.6 to $16.6 \%(1,3,5,6,7)$. However, all previous studies have solely evaluated the renin stimulatory effect on aldosterone secretion without taking into consideration the adrenocorticotrophin (ACTH) effect. Following the recently introduced modification of FST, by adding dexamethasone (FDST) to suppress both renin and ACTH effect on aldosterone secretion, the prevalence of PA was found to be as high as 31\% $(8,9)$.

Making the diagnosis of PA is highly relevant as the clinical signs and symptoms of PA and routine biochemistry are not specific, whereas even mild undiagnosed PA may lead to renal impairment, atrial fibrillation, stroke, and/ or myocardial infarction $(10,11,12,13)$. Considering the high prevalence of hypertension in the general population and the high prevalence of PA among hypertensive individuals, reliable, easy-to-perform, and cost-effective diagnostic tests are required for early diagnosis of PA (14).

Making an early diagnosis entails the application of specific treatment by either surgical removal of the hyper-functioning adrenal lesion(s) or administration of targeted medical treatment with mineralocorticoid receptor antagonists (MRAs). However, currently available diagnostic tests for PA are complex, time-consuming, relatively expensive, and therefore cannot be applied widely in primary care units. In order to overcome these limitations, we opted to develop a new rapid overnight diagnostic test for PA aiming at suppressing with appropriate targeted drugs the renin-angiotensinaldosterone system (RAAS), such as captopril and valsartan, and concomitantly suppress ACTH secretion with the administration of dexamethasone. The diagnostic accuracy of the new test will be evaluated using the wellvalidated FDST $(8,9)$.

\section{Patients and methods}

We evaluated 148 hypertensive patients, aged 31-71 years, who were investigated for hypertension in our department from 2011 to 2015. Subjects already receiving antihypertensive treatment were considered to be hypertensives and had the date of the diagnosis of hypertension and prescribed medications recorded. Home blood pressure (BP) monitoring was used for assessing the BP status of the participants. Participants were asked to record their BP twice daily (morning and evening) for 7 days. For each BP recording, subjects were instructed to take two consecutive measurements at least $1 \mathrm{~min}$ apart while seated. After discarding the measurements of the first day, we calculated the average value of the remaining measurements to establish the diagnosis of hypertension (systolic BP (SBP) >140 and/or diastolic BP (DBP) >90 mmHg) (15). Exclusion criteria were the presence of cardiovascular, renal or hepatic disease; past or present malignancies; and/or rheumatologic diseases. All participants were euthyroid at their initial visit and remained so during the follow-up period. Postmenopausal women did not receive any hormonal replacement therapy. The reporting of the study conformed to the Strengthening the Reporting of Observational Studies in Epidemiology statement and guidelines. The study protocol was approved by the institution's ethics committee, and informed consent was obtained from all the study participants. At baseline, all participants underwent recording of their medical history and a routine physical examination, including documentation of anthropometric characteristics (weight $(\mathrm{kg})$, height $(\mathrm{cm})$, waist circumference $(\mathrm{cm})$ and body mass index (BMI) $\left(\mathrm{kg} / \mathrm{m}^{2}\right)$ ) by the same physician (V Tsiavos).

All hypertensive patients receiving antihypertensive therapy known to affect the renin-aldosterone axis were converted to calcium channel blockers at least 3 weeks before any adrenal hormonal measurement was performed. The newly diagnosed hypertensive patients were also treated with calcium channel blockers. Blood sampling for routine biochemistry and a full blood count were performed, and all participants underwent a FDST as described previously (8). Briefly, fludrocortisone acetate $0.1 \mathrm{mg} / 6 \mathrm{~h}$ per os (PO) and $4 \mathrm{~g}$ sodium chloride with meals three times daily were given for 4 days. In addition, $2 \mathrm{mg}$ dexamethasone PO was given at 24:00 h of the fourth day, at least $2 \mathrm{~h}$ after the last meal. A blood sample was taken the morning (08:30-9:00 h) of the next day for cortisol (F), aldosterone (ALD), renin (REN), and ACTH measurements, as well as for the calculation of the ALD:REN ratio (ARR). Supplementation with potassium gluconate $(4.68 \mathrm{~g} / 8 \mathrm{~h})$ was given to all participants during the FDST to maintain serum $\mathrm{K}^{+}$levels within the normal range (3.5-5.5 mEq L). In addition, all participants also underwent the overnight diagnostic test (DCVT). The two tests were performed at least 7-13 days apart each other. On the day of the test, the patients did not take their treatment with calcium channel blockers. The rationale of the test was to eliminate all factors known to exert a stimulatory effect on aldosterone secretion acting at various points of aldosterone production. Thus, captopril was administered to inhibit ACE activity, valsatan to counteract the remaining angiotensin activity at the receptor level, and dexamethasone to suppress the ACTH 
effect. The ACE inhibitor captopril was preferred because its rapid action within 60-90 min (16) and valsartan because of its high affinity to the AT-I receptor (17). Therefore, all participants received $2 \mathrm{mg}$ dexamethasone, $50 \mathrm{mg}$ captopril, and $320 \mathrm{mg}$ valsartan at midnight, at least $2 \mathrm{~h}$ after the last meal the day before the early morning sampling for hormones' measurements to avoid the wellknown effect of food on these drugs adsorption. Next morning, due to its short half-life, an extra dose of $50 \mathrm{mg}$ captopril was given $1 \mathrm{~h}$ before blood sampling, which was performed between 08:30 and 09:00 $\mathrm{h}$ for measurement of circulating cortisol, ALD, REN, ACTH, and potassium levels as well as for the calculation of the ARR. All blood samples were drawn with the participants remaining seated in a non-stressful environment for at least $30 \mathrm{~min}$. In order to evaluate adrenal morphology, computerized tomography (CT) scan of the adrenal glands with $2 \mathrm{~mm}$ sections using the Philips Brilliance 16 Spiral scanner was performed in all participants. Adrenal adenomas were defined as well-circumscribed adrenal lesions greater than $10 \mathrm{~mm}$ with a non-contrast CT attenuation coefficient of less than 10 Hounsfield units.

\section{Hormonal measurements}

Hormonal measurements for ALD, REN, F, and ACTH were performed as described previously (8).

\section{Statistical analysis}

Statistical analysis was performed using the SPSS software package (SPSS, version 17.0). A Student's $t$-test and the nonparametric Mann-Whitney test were used to compare the continuous variables with and without normal distribution respectively. The $\chi^{2}$ test was used for comparison of categorical variables. The mean \pm S.E.M was used to express the results, whereas $P<0.05$ was considered statistically significant. The $97.5 \%$ percentiles were used to define the upper normal cutoffs for aldosterone suppression. Receiver operating characteristic (ROC) curves have been applied to assess the sensitivity and specificity of the post-FDST and DVCT ARR and ALD levels.

\section{Results}

All participants' anthropometric characteristics and biochemical profile are presented in Table 1 . The diagnosis of PA was based on the normal cutoffs of post-FDST ALD levels and ARR, $3 \mathrm{ng} / \mathrm{dL}(84 \mathrm{pmol} / \mathrm{L})$ and $0.9 \mathrm{ng} / \mathrm{dL} / \mu \mathrm{U} / \mathrm{mL}(26 \mathrm{pmol} / \mathrm{IU})$ respectively, as defined in previous studies $(9,18)$. Using these normal cutoffs, 41 (28\%) patients (148) were diagnosed with PA. However, another four patients were also considered to have PA, although they had a negative FDST, as they presented with uncontrolled hypertension under treatment with two to three antihypertensive drugs, and had spontaneous hypokalemia, suppressed renin levels, and kaliuresis, while all of them normalized their blood pressure after administration of spironolactone or eplerenone. The postFDST ALD levels and ARR of these four patients ranged from 1.1 to $2.2 \mathrm{ng} / \mathrm{dL}$ (30.7-61.6 pmol/L) and 0.3 to $2 \mathrm{ng} /$ $\mathrm{dL} / \mu \mathrm{U} / \mathrm{mL}$ (8-56 pmol/IU) respectively (Supplementary Table 1, see section on supplementary data given at the end of this article). Only these four patients among the tested hypertensives completed the FDST with significant hypokalemia $\left(\mathrm{K}^{+}\right.$levels: $\left.2.5-3.1 \mathrm{mEq} / \mathrm{L}\right)$. Among the remaining $41 \mathrm{PA}$ patients who were positive on FDST,

Table 1 Anthropometric characteristics and biochemical parameters of essential hypertensives (EH) and patients with primary aldosteronism (PA). Data are presented as mean \pm S.E.M.

\begin{tabular}{lr}
\hline & All patients \\
\cline { 1 - 2 } Age (years) & 148 \\
$\mathrm{SBP}(\mathrm{mmHg})$ & $53.60 \pm 1.10$ \\
$\mathrm{DBP}(\mathrm{mmHg})$ & $139.30 \pm 1.50$ \\
$\mathrm{BMl}\left(\mathrm{kg} / \mathrm{m}^{2}\right)$ & $85.06 \pm 0.95$ \\
$\mathrm{Na}^{+}(\mathrm{mEq} / \mathrm{L})$ & $29.25 \pm 0.43$ \\
$\mathrm{~K}^{+}(\mathrm{mEq} / \mathrm{L})$ & $139.5 \pm 0.28$ \\
$\mathrm{UrNa}^{+}(\mathrm{mEq} / 24 \mathrm{~h})$ & $3.95 \pm 0.03$ \\
$\mathrm{UrK}^{+}(\mathrm{mEq} / 24 \mathrm{~h})$ & $139.07 \pm 4.60$ \\
$\mathrm{UrK}^{+} / \mathrm{Na}^{+}$ & $65.30 \pm 2.10$ \\
\hline
\end{tabular}

\begin{tabular}{r}
\hline EH \\
\hline 103 \\
$52.90 \pm 1.30$ \\
$136.60 \pm 1.80$ \\
$83.50 \pm 1.10$ \\
$29.50 \pm 0.50$ \\
$139.30 \pm 0.15$ \\
$4.04 \pm 0.03$ \\
$140.90 \pm 5.70$ \\
$58.90 \pm 2.10$ \\
$0.41 \pm 0.02$
\end{tabular}

\begin{tabular}{ccc}
\hline PA & & EH vs PA \\
\cline { 1 - 1 } 55 & & $P$ \\
$55.00 \pm 2.00$ & & NS \\
$146.00 \pm 2.40$ & & 0.007 \\
$88.70 \pm 1.70$ & & 0.02 \\
$28.30 \pm 0.70$ & & $N S$ \\
$140.80 \pm 0.36$ & & 0.01 \\
$3.82 \pm 0.08$ & & 0.001 \\
$137.00 \pm 7.60$ & & NS \\
$82.50 \pm 4.50$ & & $<0.0001$ \\
$0.65 \pm 0.04$ & $<0.0001$ \\
\hline
\end{tabular}

$n$, number of patients; SBP, systolic blood pressure; DBP, diastolic blood pressure; BMI, body mass index; $\mathrm{UrNa}^{+}, \mathrm{UrK}^{+}, \mathrm{UrK}^{+} / \mathrm{Na}^{+}, 24 \mathrm{~h} \mathrm{urinary} \mathrm{Na}^{+}, \mathrm{K}^{+}$, and $\mathrm{K}^{+}: \mathrm{Na}^{+}$ratio respectively; NS, not significant. 
seven $(17 \%)$ had also low end-test $\mathrm{K}^{+}$levels ranging from 3.1 to $3.4 \mathrm{mEq} / \mathrm{L}$, whereas among the $\mathrm{EH}$ patients, only eight $(7.8 \%)$ had low end-test $\mathrm{K}^{+}$levels ranging from 3.2 to $3.4 \mathrm{mEq} / \mathrm{L}$. In order to exclude a false positive test, all these four patients were asked to repeat the test. However, only one from these four patients, with postFDST ALD levels 1.5 (43 pmol $/ \mathrm{L})$, ARR $0.6 \mathrm{ng} / \mathrm{dL} / \mu \mathrm{U} / \mathrm{mL}$ $(21 \mathrm{pmol} / \mathrm{L})$ and $\mathrm{K}^{+} 2.5 \mathrm{mEq} / \mathrm{L}$, agreed to repeat the FDST after normalization of serum $\mathrm{K}^{+}$levels with IV potassium administration. She was a 63-year-old obese lady (BMI: 35.50 ) with well-controlled diabetes mellitus on $850 \mathrm{mg}$ metformin daily, arterial hypertension diagnosed at the age of 52 years, low normal serum $\mathrm{K}^{+}$levels (usually), spontaneous hypokalemia (occasionally), suppressed renin levels $(2 \mathrm{U} / \mathrm{L})$, and kaliuresis $(86.2 \mathrm{mEq} / 24 \mathrm{~h})$, whereas CT examination revealed a right adrenal adenoma $(2.5 \mathrm{~cm})$. Following normalization of serum $\mathrm{K}^{+}$ levels $(4.1 \mathrm{mEq} / \mathrm{L})$, the post-FDST ALD levels and ARR were $6 \mathrm{ng} / \mathrm{dL}(167 \mathrm{pmol} / \mathrm{L})$ and $3 \mathrm{ng} / \mathrm{dL} / \mu \mathrm{U} / \mathrm{mL}(85 \mathrm{pmol} / \mathrm{IU})$ respectively, confirming the diagnosis of PA. Therefore, 42 (28.4\%) of the participants were considered to have PA, the three PA patients who failed to be diagnosed by FDST were characterized as almost certainly PA and were excluded from the final statistical analysis, whereas the remaining 103 were diagnosed as having essential hypertension (EH) (Fig. 1 and Table 2).

The group of patients with EH (103) were considered as a control for the overnight DCVT, as normotensive volunteers could not be used to define the normal cutoffs of the test. Using the $97.5 \%$ percentiles, derived from the $\mathrm{EH}$ patients, the normal cutoffs for post-DCVT ALD level and post-DCVTARRwere $5.8(162 \mathrm{pmol} / \mathrm{L})$ and $0.9 \mathrm{ng} / \mathrm{dL} / \mu \mathrm{U} / \mathrm{mL}$ (25 pmol/IU) respectively. However, further analysis of the results showed that in ten $(9.7 \%) \mathrm{EH}$ patients, the postDCVT ARR was inappropriately high, ranging from 0.9 to $1.3 \mathrm{ng} / \mathrm{dL} / \mu \mathrm{U} / \mathrm{mL}$ (25-36 pmol/IU), and was regarded as a false positive result, as the post-DCVT ALD levels were low, not compatible with autonomous aldosterone production, and the post-DCVT REN levels suppressed. In addition, in 15 (14.5\%) EH patients, the post-DCVT ALD levels were found to be inappropriately elevated ranging from 3 to $12 \mathrm{ng} / \mathrm{dL}$ ( $85-340 \mathrm{pmol} / \mathrm{L})$, false positive results, compatible with autonomous aldosterone secretion, following a rise in REN levels (range $46-322 \mu \mathrm{U} / \mathrm{mL}$ ), usually above the upper normal limit, giving, however, a low post-DVCT ARR.

The performance characteristics of the two tests used were compared by estimating the sensitivity and specificity of the post-FDST and post-DCVT ALD levels and ARR in diagnosing PA using ROC analysis
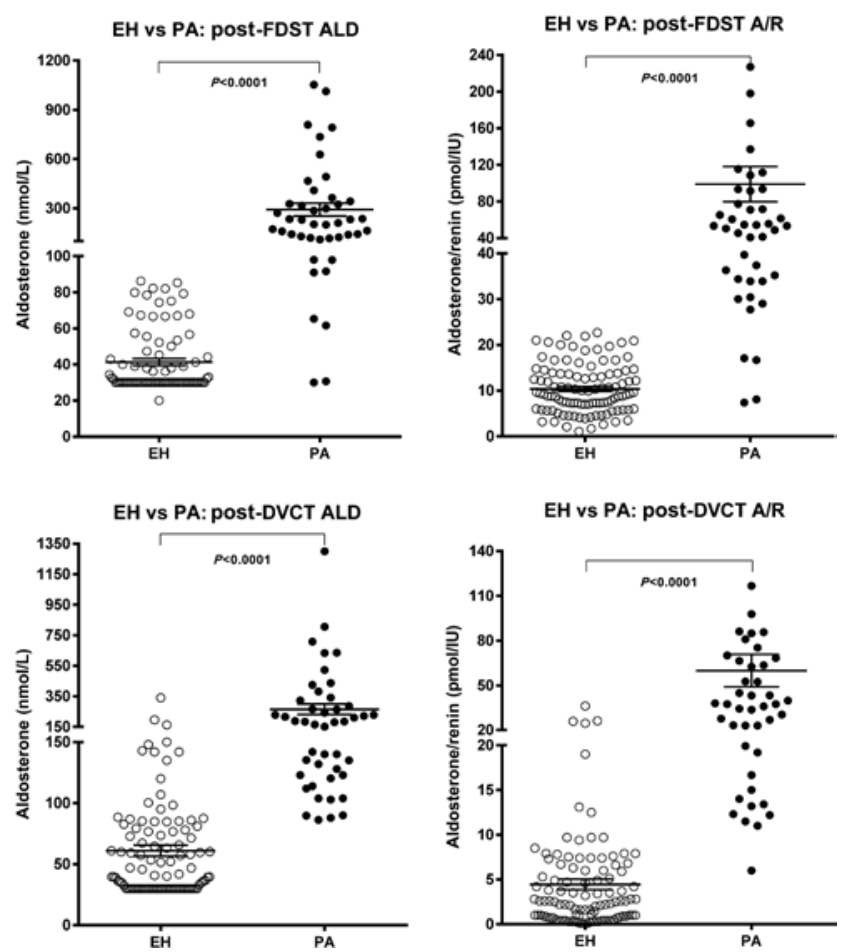

Figure 1

Post-FDST and post-DVCT aldosterone (ALD) levels and aldosterone:renin ratios (ARR) in essential hypertensives (EH) vs patients with primary aldosteronism (PA). The horizontal lines represent the mean \pm S.E.M.

(Table 3). The estimated sensitivity and specificity for the post-FDST ARR was $100 \%$ with a selected cutoff of $0.9 \mathrm{ng} / \mathrm{dL} / \mu \mathrm{U} / \mathrm{mL}(26 \mathrm{pmol} / \mathrm{IU})$ and for post-FDST ALD levels $100 \%$ and $81.5 \%$ with a selected cutoffs of $3.1 \mathrm{ng} /$ $\mathrm{dL}(85 \mathrm{pmo} / \mathrm{L})$ respectively. Using the post-FDST ARR, no false positive results were observed in this study; thus, the simultaneous consideration of the post-FDST ALD levels was not considered necessary, as no improvement in the diagnostic accuracy of the test was expected. The corresponding sensitivity and specificity for the postDCVT ARR were 98 and 89\%, respectively, and for the post-DCVT ALD 100\% and 82\% with selected cutoffs of $0.3 \mathrm{ng} / \mathrm{dL} / \mu \mathrm{U} / \mathrm{mL}(9 \mathrm{pmol} / \mathrm{IU})$ and $3.1 \mathrm{ng} / \mathrm{dL}(85 \mathrm{pmol} / \mathrm{L})$ respectively. However, considering these cutoffs for the post-DCVT ALD and post-DCVT ARR simultaneously, the estimated sensitivity and specificity, using the procedure described by Barry and Ebell (19), were 98 and 100\% respectively. Applying these cutoffs, the diagnosis of PA was confirmed in $44(98 \%)$ of the 45 patients who were considered as having the disease, including the four patients in whom the FDST failed initially to confirm 
Table 2 Basal and post-FDST/post-DCVT hormonal levels among patients with essential hypertension (EH) and primary aldosteronism (PA). Data are presented as mean \pm S.E.M.

\begin{tabular}{l}
\hline \\
\hline$n$ \\
Basal ALD $(\mathrm{ng} / \mathrm{dL})$ \\
Basal REN $(\mu \mathrm{U} / \mathrm{mL})$ \\
Basal RR $(\mathrm{ng} / \mathrm{dL} / \mu \mathrm{U} / \mathrm{mL})$ \\
Basal F $(\mu \mathrm{g} / \mathrm{dL})$ \\
Basal ACTH $(\mathrm{pg} / \mathrm{mL})$ \\
Urinary F $(\mu \mathrm{g} / 24 \mathrm{~h})$ \\
Post-FDST F $(\mu \mathrm{g} / \mathrm{dL})$ \\
Post-FDST ACTH $(\mathrm{pg} / \mathrm{mL})$ \\
Post-FDST ALD $(\mathrm{ng} / \mathrm{dL})$ \\
Post-FDST REN $(\mu \mathrm{U} / \mathrm{mL})$ \\
Post-FDST ARR $(\mathrm{ng} / \mathrm{dL} / \mu \mathrm{U} / \mathrm{mL})$ \\
Post-FDST K $(\mathrm{mEq} / \mathrm{L})$ \\
Post-DCVT F $(\mu \mathrm{g} / \mathrm{dL})$ \\
Post-DCVT ACTH $(\mathrm{pg} / \mathrm{mL})$ \\
Post-DCVT ALD $(\mathrm{ng} / \mathrm{dL})$ \\
Post-DCVT REN $(\mu \mathrm{U} / \mathrm{mL})$ \\
Post-DCVT ARR $(\mathrm{ng} / \mathrm{dL} / \mu \mathrm{U} / \mathrm{mL})$ \\
Post-DCVT K ${ }^{+}(\mathrm{mEq} / \mathrm{L})$
\end{tabular}

\begin{tabular}{c}
\hline EH \\
\hline 103 \\
$10.89 \pm 1.31$ \\
$19.01 \pm 1.45$ \\
$0.62 \pm 0.04$ \\
$13.46 \pm 0.52$ \\
$20.52 \pm 1.90$ \\
$84.68 \pm 5.53$ \\
$1.62 \pm 0.08$ \\
$6.44 \pm 0.23$ \\
$1.49 \pm 0.07$ \\
$5.30 \pm 0.30$ \\
$0.40 \pm 0.02$ \\
$3.88 \pm 0.04$ \\
$1.86 \pm 0.09$ \\
$6.38 \pm 0.24$ \\
$2.224 \pm 0.25$ \\
$62.40 \pm 9.20$ \\
$0.11 \pm 0.01$ \\
$4.42 \pm 0.04$
\end{tabular}

\begin{tabular}{c}
\hline PA \\
\hline 45 \\
$20.38 \pm 2.43$ \\
$5.32 \pm 0.44$ \\
$7.51 \pm 1.73$ \\
$15.59 \pm 0.91$ \\
$22.77 \pm 2.90$ \\
$71.50 \pm 7.20$ \\
$2.14 \pm 0.22$ \\
$5.60 \pm 0.25$ \\
$10.51 \pm 1.42$ \\
$4.46 \pm 0.46$ \\
$3.62 \pm 0.70$ \\
$3.58 \pm 0.07$ \\
$2.32 \pm 0.20$ \\
$6.03 \pm 0.23$ \\
$9.50 \pm 1.33$ \\
$6.70 \pm 0.70$ \\
$2.14 \pm 0.40$ \\
$3.86 \pm 0.07$
\end{tabular}

\begin{tabular}{cc}
\hline $\boldsymbol{P}$ \\
\hline$<0.0001$ \\
$<0.0001$ \\
$<0.0001$ \\
NS \\
NS \\
NS \\
NS \\
NS \\
$<0.0001$ \\
0.01 \\
$<0.0001$ \\
$<0.0001$ \\
NS \\
NS \\
$<0.0001$ \\
$<0.0001$ \\
$<0.0001$ \\
$<0.0001$ \\
\hline
\end{tabular}

$n$, number of patients; ALD, aldosterone; REN, renin; ARR, aldosterone:renin ratio; F, cortisol; ACTH, adrenocorticotropic hormone, FDST, fludrocortisone-dexamethasone-saline test, DCVT, dexamethasone-captopril-valsartan test; NS, not significant.

the diagnosis (Fig. 1). The single PA patient who failed to be diagnosed by DCVT was a 48-year-old lady with a mild form of arterial hypertension diagnosed at the age of 46 years, normal serum $\mathrm{K}^{+}$levels $(3.7 \mathrm{mEq} / \mathrm{L})$ without kaliuresis $(<60 \mathrm{mEq} / 24 \mathrm{~h})$, low normal basal renin levels (7 U/L), and significantly increased post-FDST ALD and ARR (11.64 ng/dL (323 pmol/L) and $2.0 \mathrm{ng} / \mathrm{dL} / \mu \mathrm{U} / \mathrm{mL}$ (55.7 pmol/IU) respectively), whereas CT examination revealed a left adrenal adenoma $(2.6 \mathrm{~cm})$.

Of particular importance was the effect of FDST and DCVT on serum $\mathrm{K}^{+}$levels. FDST induced a significant decrease in serum $\mathrm{K}^{+}$levels in both $\mathrm{EH}$ patients (mean \pm S.E.M., baseline: $4.04 \pm 0.03 \mathrm{mEq} / \mathrm{L}$, post-FDST: $3.88 \pm 0.04 \mathrm{mEq} / \mathrm{L}$, $P=0.0006)$ and PA patients (mean \pm s.E.M., baseline: $3.82 \pm 0.08 \mathrm{mEq} / \mathrm{L}$, post-FDST: $3.58 \pm 0.07 \mathrm{mEq} / \mathrm{L}, P=0.01)$.
By contrast, DCVT induced a significant increase in serum $\mathrm{K}^{+}$levels in $\mathrm{EH}$ patients (mean \pm s.E.M., baseline: $4.04 \pm 0.03 \mathrm{mEq} / \mathrm{L}, \quad$ post-DCVT: $\quad 4.42 \pm 0.04 \mathrm{mEq} / \mathrm{L}$, $P<0.0001)$, whereas the test did not affect serum $\mathrm{K}^{+}$levels in patients with PA (mean \pm s.E.M., baseline: $3.82 \pm 0.08 \mathrm{mEq} / \mathrm{L}$, post-DCVT: $3.86 \pm 0.07 \mathrm{mEq} / \mathrm{L}, P=0.41)$.

The anthropometric characteristics and biochemical profile of EH and PA patients are presented in Table 1. There were no significant differences regarding age, BMI and urinary $\mathrm{Na}^{+}$concentrations between $\mathrm{EH}$ and PA patients, whereas serum $\mathrm{K}^{+}$level was significantly lower and SBP, DBP, serum $\mathrm{Na}^{+}$, urinary $\mathrm{K}^{+}$, and urinary $\mathrm{K}^{+}: \mathrm{Na}^{+}$ratio were significantly higher in PA compared with EH patients. Basal and post-FDST hormone levels are presented in Table 2. Basal serum cortisol

Table 3 Normal cutoffs and performance characteristic of the tests, as they defined by ROC analysis.

\begin{tabular}{|c|c|c|c|c|c|}
\hline & $\begin{array}{c}\text { Controls } \\
\text { (normal cutoffs) }\end{array}$ & $\begin{array}{c}\text { PA patients with } \\
\text { values > normal } \\
\text { cutoffs }\end{array}$ & $\begin{array}{c}\text { EH patients with } \\
\text { values < normal } \\
\text { cutoffs }\end{array}$ & Sensitivity (\%) & Specificity (\%) \\
\hline Post-FDST ALD (ng/dL) & 3 & $41 / 45$ & $103 / 103$ & 91 & 100 \\
\hline Post-FDST ARR (ng/dL/ $\mu \mathrm{U} / \mathrm{mL}$ ) & 0.9 & $41 / 45$ & $103 / 103$ & 91 & 100 \\
\hline $\begin{array}{l}\text { Post-FDST ALD (ng/dL) and } \\
\text { post-FDST ARR (ng/dL/ } / \mu \mathrm{U} / \mathrm{mL})\end{array}$ & $3 / 0.9$ & $41 / 45$ & $103 / 103$ & 91 & 100 \\
\hline Post-DCVT ALD (ng/dL) & 3 & $45 / 45$ & $86 / 103$ & 100 & 83 \\
\hline Post-DCVT ARR (ng/dL/ $\mu \mathrm{U} / \mathrm{mL})$ & 0.3 & $44 / 45$ & 93/103 & 98 & 90 \\
\hline $\begin{array}{l}\text { Post-DCVT ALD (ng/dL) and } \\
\text { post-DCVT ARR }(\mathrm{ng} / \mathrm{dL} / \mu \mathrm{U} / \mathrm{mL})\end{array}$ & $3 / 0.3$ & $44 / 45$ & $103 / 103$ & 98 & 100 \\
\hline
\end{tabular}

ALD, aldosterone; ARR, aldosterone:renin ratio; FDST, fludrocortisone-dexamethasone-saline test; DCVT, dexamethasone-captopril-valsartan test. 
(F), ACTH and 24-h urinary F, and post-FDST/DCVT F and ACTH levels did not differ significantly between EH and PA patients, whereas basal and post-FDST/ DCVT ALD, REN, $\mathrm{K}^{+}$levels, and ARR were found to be significantly higher in PA patients $(0.01$ to $<0.0001)$. CT examination revealed that $19(42.20 \%)$ patients with PA had an adrenal adenoma, a prevalence significantly higher than that observed in patients with EH $(22 / 103,21.40 \%)(P<0.001)$.

\section{Discussion}

In this study, an overnight combined screening diagnostic test (DCVT) for PA is described using pharmaceutical RAAS blockade and is compared with the FDST, of high diagnostic accuracy, as it is based on suppressing the two main natural stimuli, renin and $\mathrm{ACTH}$, of aldosterone secretion by sodium chloride loading and concomitant dexamethasone administration. The diagnosis of PA was based on the cutoffs of post-FDST ALD levels and ARR, $3 \mathrm{ng} / \mathrm{dL}(84 \mathrm{pmol} / \mathrm{L})$ and $0.9 \mathrm{ng} / \mathrm{dL} / \mu \mathrm{U} / \mathrm{mL}(26 \mathrm{pmol} / \mathrm{IU})$ respectively, as they have been defined in normotensive volunteers recruited with strict criteria and extensively validated in previous studies $(8,9,18)$. These cutoffs were similar to those derived from the group of hypertensive patients with $\mathrm{EH}$, who were served as controls in this study. Using these cutoffs, 41 of the tested patients (148) diagnosed to have PA. However, FDST failed to reveal autonomous aldosterone secretion in another four patients who were considered to have almost certainly PA. Apparently, this FDST failure is directly related to low potassium levels found at the end test, as the negative FDST in one of these patients became positive after normalization of serum $\mathrm{K}^{+}$levels, obtaining adequate post-FDST ALD level and ARR to confirm the diagnosis of PA.

After the pharmaceutical RAAS blockade, a significant rise in renin levels associated with low or suppressed aldosterone levels giving a low ARR in EH hypertensive patients without autonomous aldosterone secretion was expected. Indeed, using a group of patients as controls, who were considered to have EH, the post-DCVT ARR was found to be low in the majority of cases. In only ten $(9.7 \%)$ patients with $\mathrm{EH}$, the post-DCVT ARR was inappropriately high and was regarded as a false positive result, as the post-DCVT ALD levels were low, not compatible with autonomous aldosterone production, and the post-DCVT REN levels suppressed. However, in another 15 (14.5\%) patients with $\mathrm{EH}$, the post-DCVT ALD levels were found to be falsely elevated (false positive results). This was an unexpected finding as such high aldosterone levels following complete blockage of renin-Ang-II system are not expected. A possible explanation for this finding could be an undefined so far rennin-dependent but Ang-II-independent mechanism or due to Ang-II escape from pharmacological blockage (20). Therefore, in 25 (24\%) patients with EH, either the post-DCVT ARR or the post-DCVT ALD levels were found to be falsely elevated (false positive results), affecting the specificity of the test when each of them was used separately. In order to exclude the diagnosis of PA from EH patients with false positive results, the simultaneous consideration of both indices of autonomous aldosterone secretion, post-DVCT ARR $0.3 \mathrm{ng} / \mathrm{dL} / \mu \mathrm{U} / \mathrm{mL}(9 \mathrm{pmol} / \mathrm{IU})$ and post-DVCT ALD $3 \mathrm{ng} / \mathrm{dL}(85 \mathrm{pmol} / \mathrm{L})$, was adopted. Using these normal cutoffs, the diagnosis of PA was confirmed in 44 of 45 (98\%) patients with PA, including the four patients in whom the FDST failed to confirm the diagnosis, as the performance characteristics of the DCVT improved significantly with an estimated specificity $100 \%$ and a sensitivity $98 \%$.

It is generally accepted that currently available diagnostic tests for PA, which are based on saline loading for RAAS suppression, are complex, timeconsuming, and relatively expensive (21). Therefore, they cannot be widely applied to hypertensive patients in primary health care units. In addition, the oral saline loading test for 4 days, which is employed by either the FDST or the classical FST, often induces a significant decrease in serum $\mathrm{K}^{+}$levels at the end of the test despite the simultaneous oral supplementation with potassium gluconate or potassium chloride. In that case, the test has to be repeated after normalization of serum $\mathrm{K}^{+}$levels with IV potassium administration, further increasing the cost and patient's inconvenience. By contrast, the use of pharmaceutical blockage, as described in the DCVT, is not expected to induce any further decrease in serum $\mathrm{K}^{+}$levels. This was exactly the case in this study where DCVT induced a significant increase in serum $\mathrm{K}^{+}$ levels in $\mathrm{EH}$ patients leaving unaffected serum $\mathrm{K}^{+}$levels in PA patients.

Although it is well known that any decrease in serum $\mathrm{K}^{+}$levels, even within the normal range, is a strong inhibitor of aldosterone secretion $(22,23)$, this effect on the diagnostic accuracy of saline loading tests has never been validated. A possible reason for this could be the lack of alternative to the saline loading tests with high diagnostic accuracy to compare with. In this study, we found that significant hypokalemia may cause FDST failure to diagnose PA in a significant number of patients 
(9\%), who were considered having the disease. These findings underline the necessity of doing the FDST, as well as any other saline loading test, with serum $\mathrm{K}^{+}$levels within the normal range.

The standard diagnostic procedure for PA that has been adopted by almost all and is recommended by the recently published guideline of Endocrine Society (24) has been to initially utilize the basal ARR as a screening test for case detection in high-risk groups of hypertensive patients, and then establish the diagnosis of PA using a confirmatory test. The FDST has been recognized as a new useful confirmatory test of PA (24), as it is sensitive, safe to be performed on an outpatient basis, and has been validated in a relatively large number of patients (9). In this respect, the number of hypertensives with PA who are diagnosed by FDST is expected to represent only a subgroup of those identified by the basal ARR. However, in recent studies (9), we have shown that after performing the FDST in all hypertensives, rather than in those only identified by the basal ARR, the number of hypertensives who had PA based on an elevated basal ARR was significantly lower than that identified by the FDST (43/327 vs 94/327). This suggests that basal ARR as a screening test may diagnose only the more severe cases leaving undiagnosed the milder forms of PA. We consider that the diagnostic limitations that are related to the two-step procedure (screening + confirmatory tests) can be overcome using as a screening diagnostic test, the DCVT, which, as shown in this study, is a simple and very-low-cost test, with similar sensitivity and specificity compared with FDST.

In this study, a low-cost, rapid, safe, and easy-toperform overnight screening diagnostic test for PA is described. It is based on pharmaceutical RAAS blockade and is characterized by higher diagnostic accuracy compared with a saline loading test (FDST). Therefore, the DCVT can be widely used for the diagnosis of PA on outpatient basis in primary health care units.

Supplementary data

This is linked to the online version of the paper at http://dx.doi.org/10.1530/ EJE-16-0003.

\section{Declaration of interest}

The authors declare that there is no conflict of interest that could be perceived as prejudicing the impartiality of the research reported.

\section{Funding}

This research did not receive any specific grant from any funding agency in the public, commercial or not-for-profit sector.

\section{References}

1 Funder JW, Carey RM, Fardella C, Gomez-Sanchez CE, Mantero F, Stowasser M, Young WF Jr \& Montori VM. Case detection, diagnosis, and treatment of patients with primary aldosteronism: an endocrine society clinical practice guideline. Journal of Clinical Endocrinology and Metabolism 200893 3266-3281. (doi:10.1210/jc.2008-0104)

2 Piaditis G, Markou A, Papanastasiou L, Androulakis II \& Kaltsas G. Progress in aldosteronism: A review of the prevalence of primary aldosteronism in pre-hypertension and hypertension. European Journal of Endocrinology 2015172 R191-R203. (doi:10.1530/EJE-14-0537)

3 Rossi GP, Bernini G, Caliumi C, Desideri G, Fabris B, Ferri C, Ganzroli C, Giaccheti G, Letizia C, Maccario M et al. A prospective study of the prevalence of primary aldosteronism in 1,125 hypertensive patients. Journal of the American College of Cardiology 200648 2293-2300. (doi:10.1016/j.jacc.2006.07.059)

4 Stowasser M. Update in primary aldosteronism. Journal of Clinical Endocrinology and Metabolism 200994 3623-3630. (doi:10.1210/ jc.2009-1399)

5 Douma S, Petidis K, Doumas M, Papaefthimiou P, Triantafyllou A, Kartali N, Papadopoulos N, Vogiatzis K \& Chrysanthos Z. Prevalence of primary hyperaldosteronism in resistant hypertension: a retrospective observational study. Lancet 2008371 1921-1926. (doi:10.1016/S0140-6736(08)60834-X)

6 Stowasser M, Gordon RD, Gunasekera TG, Thanuja G, Cowley DC, Ward G, Archibald C \& Smithers BM. High rate of detection of primary aldosteronism, including surgically treatable forms, after 'non-selective' screening of hypertensive patients. Journal of Hypertension 200321 2149-2157. (doi:10.1097/ 01.hjh.0000098141.70956.53)

7 Young WF. Primary aldosteronism: renaissance of a syndrome. Clinical Endocrinology 200766 607-618. (doi:10.1111/ cen.2007.66.issue-5)

8 Gouli A, Kaltsas G, Tzonou A, Markou A, Androulakis II, Ragkou D, Vamvakidis K, Zografos G, Kontogeorgos G, Chrousos G et al. High prevalence of autonomous aldosterone secretion among patients with essential hypertension. European Journal of Clinical Investigation 2011 41 1227-1236. (doi:10.1111/j.1365-2362.2011.02531.x)

9 Papanastasiou L, Markou A, Pappa T, Gouli A, Tsounas P, Fountoulakis S, Kounadi T, Tsiama V, Dasou A, Gryparis A et al. Primary aldosteronism in hypertensive patients: clinical implications and target therapy. European Journal of Clinical Investigation 201444 697-706. (doi:10.1111/eci.2014.44.issue-8)

10 Rossi GP, Sechi LA, Giacchetti G, Ronconi V, Strazzullo P \& Funder JW. Primary aldosteronism: cardiovascular, renal and metabolic implications. Trends in Endocrinology and Metabolism 2008 19 88-90. (doi:10.1016/j.tem.2008.01.006)

11 Fritsch NM \& Schiffrin EL. Aldosterone: a risk factor for vascula disease. Current Hypertension Report 20035 59-65. (doi:10.1007/ s11906-003-0012-2)

12 Gilbert KC \& Brown NJ. Aldosterone and inflammation. Current Opinion in Endocrinology Diabetes and Obesity 201017 199-204. (doi:10.1097/MED.0b013e3283391989)

13 Carey RM. Aldosterone and cardiovascular disease. Current Opinion in Endocrinology Diabetes and Obesity 201017 194-198. (doi:10.1097/ MED.0b013e3283390fa4)

14 Carretero OA \& Oparil S. Essential hypertension. Part I: definition and etiology. Circulation 2000101 329-335. (doi:10.1161/ 01.CIR.101.3.329)

15 McManus RJ, Caulfield M \& Williams B. NICE hypertension guideline 2011: evidence based evolution. BMJ 2012344 e181. (doi:10.1136/bmj.e181)

16 Duchin KL, McKinstry DN, Cohen AI \& Migdalof BH. Pharmacokinetics of captopril in healthy subjects and in patients with cardiovascular diseases. Clinical Pharmacokinetics 198814 241-259. (doi:10.2165/00003088-198814040-00002) 
17 de Gasparo M \& Whitebread S. Binding of valsartan to mammalian angiotensin AT1 receptors. Regulatory Peptides 199559 303-311. (doi:10.1016/0167-0115(95)00085-P)

18 Markou A, Pappa T, Kaltsas G, Gouli A, Mitsakis K, Tsounas P, Prevoli A, Tsiavos V, Papanastasiou L, Zografos G et al. Evidence of primary aldosteronism in a predominantly female cohort of normotensive individuals: a very high odds ratio for progression into arterial hypertension. Journal of Clinical Endocrinology and Metabolism 201398 1409-1416. (doi:10.1210/jc.2012-3353)

19 Barry HC \& Ebell MH. Test characteristics and decision rules. Endocrinology and Metabolism Clinics of North America 199726 45-65. (doi:10.1016/S0889-8529(05)70233-4)

20 Jansen PM, Hofland J, van den Meiracker AH, de Jong FH \& Danser AH. Renin and prorenin have no direct effect on aldosterone synthesis in the human adrenocortical cell lines H295R and HAC15.
Journal of the Renin Angiotensin Aldosterone System 201213 360-366. (doi:10.1177/1470320312438792)

21 Funder JW. Primary aldosteronism: are we missing the wood for the trees? Hormone and Metabolic Research 201244 251-253. (doi:10.105 5/s-0031-1301281)

22 Himathongkam T, Dluhy RG \& Williams GH. Potassim-aldosteronerenin interrelationships. Journal of Clinical Endocrinology and Metabolism 197541 153-159. (doi:10.1210/jcem-41-1-153)

23 Bauer JH \& Gauntner WC. Effect of potassium chloride on plasma renin activity and plasma aldosterone during sodium restriction in normal man. Kidney International 197915 286-293. (doi:10.1038/ki.1979.37)

24 Funder JF, Carey RM, Mantero F, Murad MH, Reincke M, Shibata H, Stowasser M \& Young WF Jr. The management of primary aldosteronism: case detection, diagnosis, and treatment: an Endocrine Society clinical practice guideline. Journal of Clinical Endocrinology and Metabolism 2016101 1889-1916. (doi:10.1210/jc.2015-4061)

Received 2 January 2016

Revised version received 6 April 2016

Accepted 12 April 2016 